\title{
UCP2 Mitigates the Loss of Human Spermatozoa Motility by Promoting mROS Elimination
}

\author{
Xiaona Wang ${ }^{a}$ Hua Qian ${ }^{b}$ Xiaoyuan Huang ${ }^{a}$ Jinjing Li ${ }^{a}$ Jiayan Zhang ${ }^{b}$ \\ Nan Zhu ${ }^{b}$ Hua Chen ${ }^{b}$ ChunFang Zhu ${ }^{b}$ Jia Wang ${ }^{a}$ Ping Zhang ${ }^{a}$ Chunyan Jin ${ }^{a, b}$ \\ Hongshan $\mathrm{Ge}^{\mathrm{a}, \mathrm{b}, \mathrm{c}}$
}

aThe Second Affiliated Hospital and Yuying Children's Hospital of Wenzhou Medical University, Wenzhou, ${ }^{b}$ Center for Reproductive Medicine, Department of Obstetrics and Gynecology, Taizhou People's Hospital, Taizhou, 'The Fifth Affiliated Hospital of Nantong University, Taizhou, China

\section{Key Words}

Uncoupling protein $2 \cdot$ human spermatozoa motility $\bullet$ mROS

\begin{abstract}
Background/Aims: To demonstrate the function of uncoupling protein 2 (UCP2) in the regulation of human spermatozoa motility. Methods: Semen samples were collected from donors with either normal spermatozoa motility (normospermia [NS]) or poor spermatozoa motility (asthenospermia [AS]). UCP2 protein in spermatozoawas quantifiedby Western blotting. The level of mitochondrial reactive oxygen species (mROS) was evaluated by MitoSOX Red.The activityof mitochondrial membrane potential (MMP) in spermatozoa was evaluated by a JC-1 assay and the ATP level was monitored by a luciferin-luciferase assay. Results: UCP2 was expressed in both NS and AS groups, with the former exhibiting a higher level than the latter. Immunofluorescence analysis shows that UCP2 is mainly located at the midregion of human spermatozoa. The inhibition of UCP2 by a highly selective inhibitor, Genipin, results in not only impaired spermatozoa mobility $(P<.05)$ but also an elevated level of mROS $(P<.05)$, suggesting that UCP2 is involved in the maintenance of the spermatozoa mobility, which probably is achieved by promoting mROS elimination. Furthermore, $\mathrm{H}_{2} \mathrm{O}_{2}$ treatment of spermatozoa increases the mROS level coupled with the loss of spermatozoa mobility. Unexpectedly, this treatment also has a positive impact on the expression of UCP2 within a certain range of supplemental $\mathrm{H}_{2} \mathrm{O}_{2^{\prime}}$ indicating the moderate mROS level possibly serves as a feedback signal to stimulate the expression of UCP2. Finally, the treatment of spermatozoa by an ROS scavenger, $N$-acetyl-L-cysteine (NAC), decreases the level of mROS and increases the curvilinear velocity (VCL) of spermatozoa, but the UCP2 level is not affected. Conclusion: These results suggest an UCP2-mROS-motility regulatory system exists for maintaining
\end{abstract}

X. Wang and H. Qian contributed equally to this work.

Chunyan Jin

and Hongshan Ge
The $2^{\text {nd }}$ Aff. Hospital and Yuying Children's Hospital of Wenzhou Med. Univ.

Zhejiang Province, 325027 (China)

E-Mail dafeng76@126.com 
spermatozoa mobility in humans. In such a system, UCP2 fulfills its function by promoting mROS elimination, and slightly over-produced mROS in turn serves as a signal to stimulates the expression of UCP2. This regulatory system represents a new potential target for the discovery of novel pharmaceuticals for the treatment of patients with low spermatozoa motility.

\section{Introduction}

Approximate $15 \%$ to $20 \%$ of couples worldwide have infertility, with males accounting for about $40 \%$ to $50 \%$ of cases [1]. Male infertility is associated with abnormalities in various aspects, such as semen volume, spermatozoa concentration, spermatozoa motility, and morphology [2-5]. Poor spermatozoa motility (also called asthenozoospermia) is a major cause of male infertility [4-6]. Spermatozoa motility, a key indicator of semen quality, is driven by flagellae, which is dependent on an adequate and continuous supply of ATP. Lack of ATP supply [7], overproduction of reactive oxygen species (ROS) [8], calcium dyshomeostasis [6], aging [9], and certain forms of environmental pollution [10-12] can lead to impaired spermatozoa motility.

Mitochondria plays critical roles in intracellular ATP production and maintenance of calcium homeostasis. It is also the major source of ROS. Previous studies have revealed the close relationship between morphology and functions of mitochondria and spermatozoa motility [13-15]. These studies demonstrated that the maintenance of mitochondrial homeostasis is critical for spermatozoa motility and semen quality. When mitochondria are damaged, a major outcome is the overproduction of mitochondrial reactive oxygen species (mROS), which then elevates the level of total cellular ROS. Excessive ROS can cause severe oxidative damages to spermatozoa membranes and DNA [14,16], leading to lowered integrity of these subcellular components, impaired spermatozoa motility, and subsequent infertility $[8,16,17]$. Spermatozoa motility is considered the earliest and most sensitive indicator of spermatozoa oxidative damage [17].

Uncoupling protein 2 (UCP2), a mitochondrial membrane protein, is widely expressed in mammalian tissues. UCP2 plays important roles in a variety of physiological processes, such as food intake [18], insulin secretion, and immunology [19, 20]. UCP2 is also vital to many pathological conditions [21]. However, the function of UCP2 in male reproduction remains unclear. Recently, a research group found expression of UCP2 in the spermatozoa of zebrafish and yellow catfish and revealed the close relevance between the expression of UCP2 and spermatozoa ROS level, degree of oxidative damage, and post-thaw viability [22, 23]. In human spermatozoa, the transcription of UCP2-encoding gene has been observed by quantifying mRNA,however, the UCP2 protein level was not further measured in the same study [24]. The aims of the present study are to determine the correlation between the expression of UCP2 and human spermatozoa mobility and to elucidate the underlying mechanism for the regulation of spermatozoa motility by UCP2.

\section{Materials and Methods}

\section{Spermatozoa preparation}

Human semen samples were collected from 200 male fertility evaluation donors between 25 to 35 years old accordingto World Health Organization (WHO) criteria. All participants signed a written informed consent. The study was approved by the Ethics Committee of the hospital and the protocols were carried out in accordance with the approved guidelines. Semen samples were collected by masturbation after a stipulated period of 2-7 days of abstinence. The collected semen samples were analyzed by computeraided spermatozoa analysis (CASA, IVOS, Hamilton, USA) and identifiedas normospermic $(\mathrm{NS}, \mathrm{n}=120)$ and asthenospermic (AS, $n=80$ ) according to WHO Guidelines. Spermatozoa were isolated by density gradient centrifugation after liquefaction for $15-30 \mathrm{~min}$ at $37^{\circ} \mathrm{C}$. In brief, semen samples ( $2 \mathrm{~mL}$ ) were added on top of a colloidal silica suspension (Percoll, Sigma Aldrich, UK) made of $80 \%$ and $40 \%$ layers (1 mL each), and 


\section{Cellular Physiology Cell Physiol Biochem 2018;50:952-962 \begin{tabular}{l|l} 
and Biochemistry Published online:23 October 2018 & $\begin{array}{l}\text { (c) 2018 The Author(s). Published by S. Karger AG, Basel } \\
\text { www.karger.com/cpb }\end{array}$ \\
\hline
\end{tabular}}

Wang et al.: Roles of UCP2 in Human Spermatozoa

centrifuged at 1, $300 \times \mathrm{g}$ for $15 \mathrm{~min}$. Then the pellets were collected and washed twice with HTF medium (Quinn's, SAGE, USA). Finally,the spermatozoa were resuspended in HTF medium.

\section{Immunofluorescence staining}

Spermatozoa were fixed using $4 \%$ paraformaldehyde for $15 \mathrm{~min}$. Spermatozoa membrane was permeated with cold $95 \%$ ethyl alcoholfor $15 \mathrm{~min}$. After washing, spermatozoa were blocked for $1 \mathrm{~h}$ with $1 \%$ fetal bovine serum (FBS) in phosphate-buffered saline (PBS). The spermatozoa were incubated with mouse polyclonal anti-UCP2 (1:50, Abcam) for $4 \mathrm{~h}$ at room temperature, and then withFITC-conjugated anti-mouse (1:5000, Bioword) for $2 \mathrm{~h}$ atroom temperature. Cells were then rinsed with PBS three times for $5 \mathrm{~min}$ each. The negative control was only incubated withsecondary antibody. Images were captured by an Olympus FluoView FV500 microscope.

\section{Western blotting}

Semen samples were incubated with $100 \mu \mathrm{l}$ SDS lysis buffer (Beyotime, China) for $30 \mathrm{~min}$ and then centrifuged at $12,000 \times \mathrm{g}$ for $10 \mathrm{~min}$ at $4{ }^{\circ} \mathrm{C}$, and the supernatant was analyzed for protein concentration. Equal amount of protein $(40 \mu \mathrm{g})$ was separated by $12 \%$ SDS-PAGE and transferred to PVDF membrane (Millipore, USA).The membranes were blocked with 5\% non-fat milk for 1 hour at room temperature. After that the membranes were then incubated overnight at $4{ }^{\circ} \mathrm{C}$ with primaryantibodies of both polyclonal antiUCP2 (1:500, Abcam, USA) and polyclonal anti- $\beta$-actin (1:200, Boster, China) followed by the incubation with HRP-conjugated anti-rabbit IgG secondary antibodies (1:500, Beyotime, China) for $2 \mathrm{~h}$ at room temperature, and then washed three times with Tris-buffered saline containing $0.1 \%$ Tween 20 (TBST). The chemiluminescence signal was captured using Super Signal West Pico (Pierce, USA), and the results were analyzed using Quantity One software (AlphaEaseFc).

\section{Measurement of ATP content}

The ATP content of spermatozoa samples was measured using the ATP Detection Kit (Beyotime, China). Spermatozoa samples were lysed by ATP lysis buffer for $30 \mathrm{~min}$, and then centrifuged at $12,000 \times \mathrm{g}$ for $10 \mathrm{~min}$ at $4{ }^{\circ} \mathrm{C}$. The supernatant $(40 \mu \mathrm{l})$ after being mixed with $100 \mu \mathrm{l}$ ATP detection buffer was added into 96-well black plates. The ATP content (nmol/mg) was analyzed using an automatic microplate reader (Biotek, USA).

\section{Measurement of mitochondrial membrane potential}

The mitochondrial membrane potential (MMP) was analyzed with a JC-1 kit (Sigma). The spermatozoa samples $\left(1 \sim 2 \times 10^{6} / \mathrm{mL}\right)$ were washed with PBS, and incubated with $1.5 \mu \mathrm{l} \mathrm{JC}-1$ working solution $(2.5 \mathrm{mg} /$ $\mathrm{mL}$ ) at $37^{\circ} \mathrm{C}$ for $30 \mathrm{~min}$. After washing with PBS, the spermatozoa samples were suspended and analyzed by Flow Cytometry (BD, USA). Ten thousand spermatozoa were recorded in each group, and the MMP level was calculated using the ratio of green florescence intensity to red florescence intensity.

\section{Measurement of ROS content in mitochondria}

The ROS content in mitochondria (mROS) was measured using MitoSOX ${ }^{\mathrm{TM}}$ Red (Invitrogen). Spermatozoa were incubated with $10 \mu \mathrm{M}$ Mitosox at $37^{\circ} \mathrm{C}$ for $10 \mathrm{~min}$. Then samples were washed with PBS and analyzed for mROS content using Flow Cytometry. Ten thousand spermatozoa were recorded in each group, and the mean fluorescent intensity (MFI) was measured in a PE channel.

\section{Statistical Analysis}

All data wasanalyzed by one-way ANOVA followed by a post-hoc comparison test using either LSD (when equal variances were assumed) or Dunnett's T3 (when equal variances were not assumed) method when more than two groups were compared. The data was presented as the mean \pm SEM, with a statistically significant difference defined as $P<0.05$. All the statistical procedures were performed using SPSS 18.0. 


\section{Cellular Physiology Cell Physiol Biochem 2018;50:952-962 \begin{tabular}{ll|l} 
and Biochemistry Published online: 23 October 2018 & $\begin{array}{l}\text { C } 2018 \text { The Author(s). Published by S. Karger AG, Basel } \\
\text { www.karger.com/cpb }\end{array}$ \\
\hline
\end{tabular}

\section{Results}

Expression of UCP2 in human spermatozoa and its correlation with spermatozoa motility

In human spermatozoa, the transcription of UCP2-encoding gene has been observed by quantifying mRNA level [24], but no study has been performed to track UCP2 expression at the protein level. In the present study, to determine whether the UCP2 protein is expressed in human spermatozoa, the prepared spermatozoa were subjected to immunofluorescence staining using antibodies against UCP2. The results shown in Fig. 1A strongly suggest that UCP2 is expressed in human spermatozoa and mainly located at the mid-region of spermatozoa. To our knowledge, this is the first time that the UCP2 protein is found to be expressed in human spermatozoa. Moreover, the UCP2 protein levels of both NS and AS groups were quantified and compared by western blotting to investigate the correlation of UCP2 expression and spermatozoa motility. The results show that the UCP2 expression is significantly higher in the NS group than in the AS group $(P<0.05$, Fig. 1B), indicating that UCP2 is likely involved in the regulation of spermatozoa motility.

Effect of the UCP2-specific inhibitor on spermatozoa motility, mROS content, and mitochondrial function

To furtherunderstand howUCP2 regulates spermatozoamotility,Genipin(SigmaChemical Co., St. Louis, MO, USA), a highly selective UCP2 inhibitor, was used to block UCP2 activity. The concentrations of Genipin used in this study are based on a published study [23]. Interestingly, as shown in Fig. 2B, the progressive motility (PR), the total motility (progressive plus nonprogressive motility), and the curvilinear velocity (VCL) of spermatozoa are all remarkably decreased in the presence of Genipin $(P<0.05)$. A significant increase inthe mROS level is observed after Genipin treatment $(P<0.05$, Fig. $2 \mathrm{C})$. On the other hand, no significant difference is observed for mitochondrial membrane potential (MMP) activity and ATP content between Genipin-treated and nontreated spermatozoa $(P>0.05$, Fig. 2D and 2E),

Fig. $\quad$ 1. UCP2 expression in human s permatozoa. (A) Immunofluorescence images show that UCP2 is located in the neck of sperm. Right images are the magnification of arrows indicated areas. Scale bars: 50micro-m. (B) UCP2 protein levels in both NS and AS groups were quantified and compared by western blotting. The optical density values were normalized to $\beta$-actin loading control, and means \pm SD were graphed (relative expression) to semiquantitatively compare the protein levels. Difference with ${ }^{*} \mathrm{P}<0.05$ (AS group versus NS group).
A

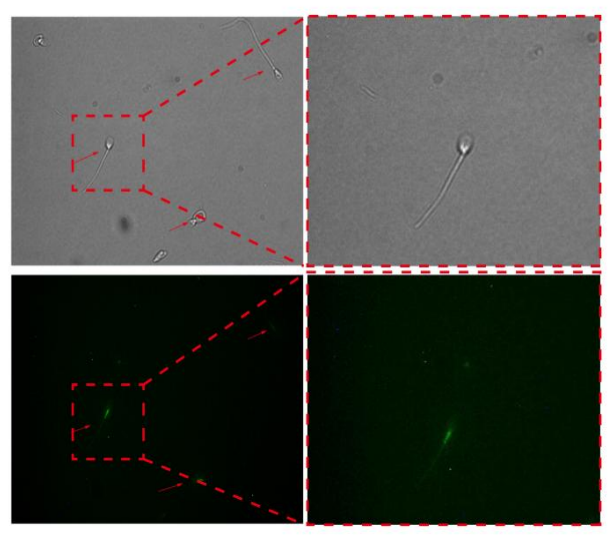

B

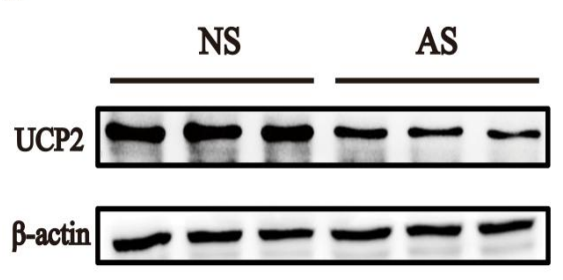

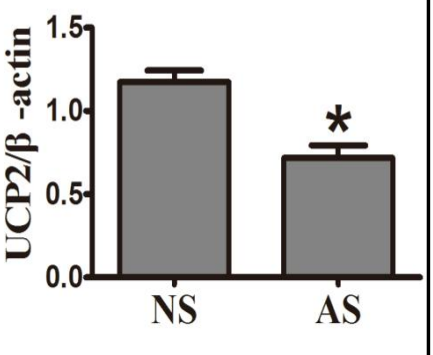


A
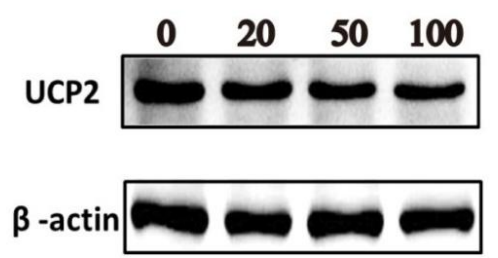

B

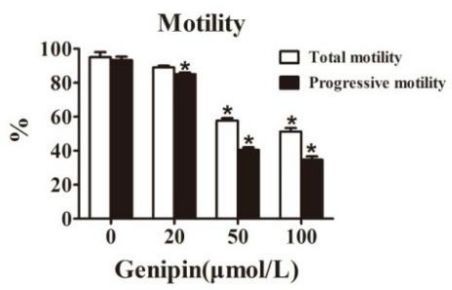

C
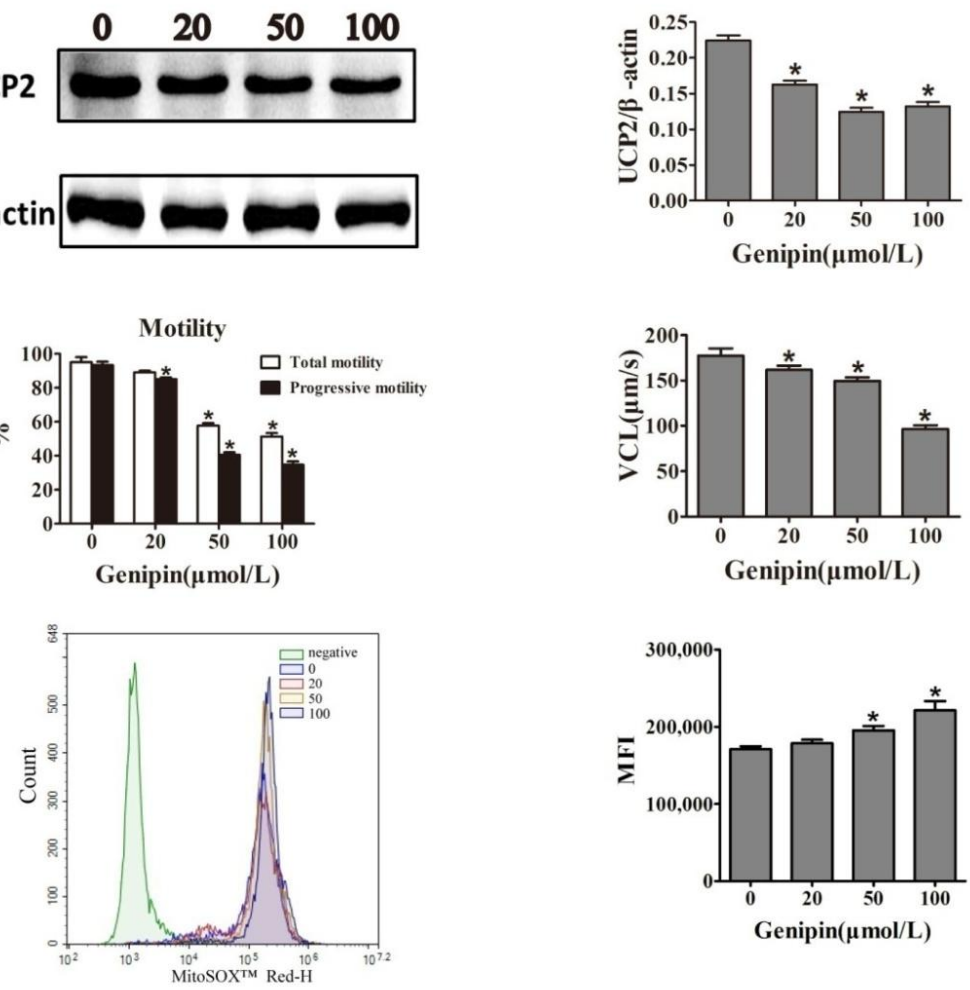

D
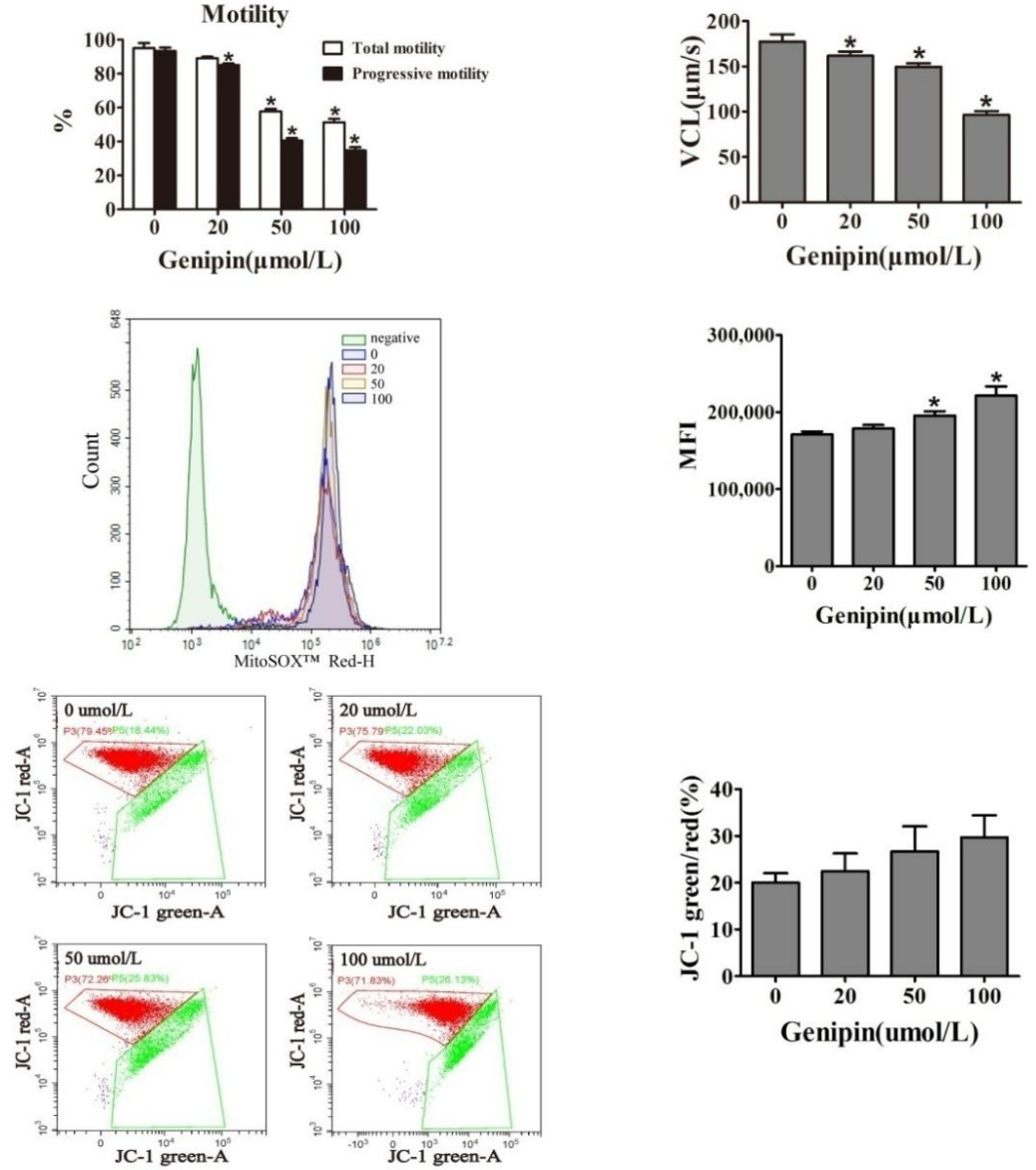

$\mathrm{E}$
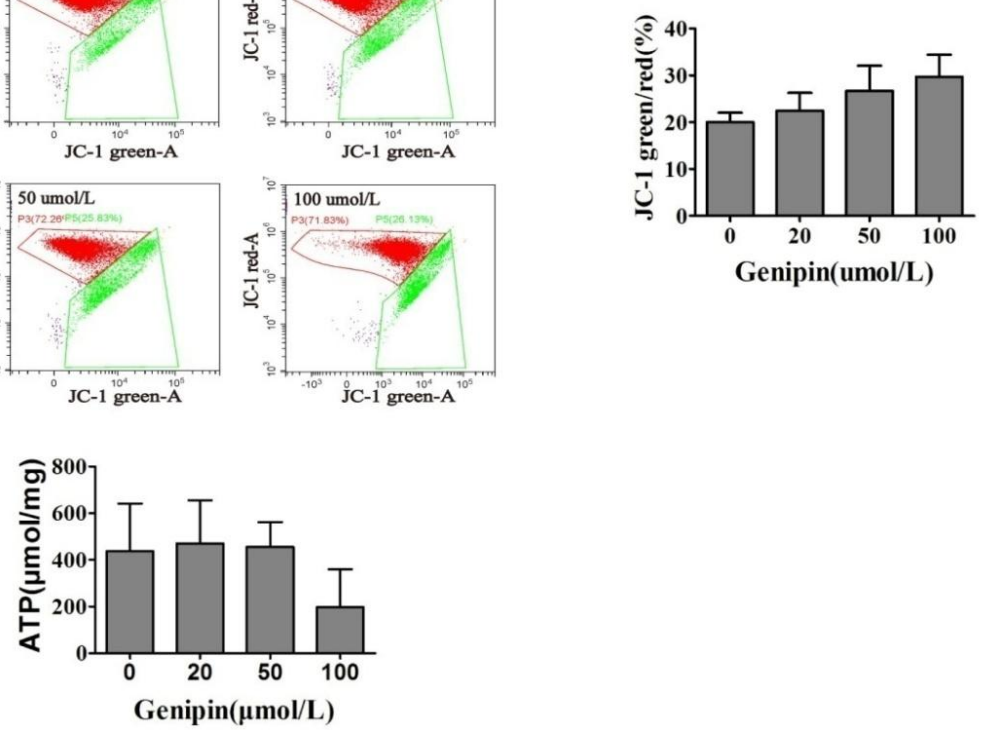

Fig. 2. Effects of the UCP2 inhibition on spermatozoa motility, mROS content, and mitochondrial function. (A) UCP2 protein levels were analyzed using western blot. The values were normalized to $\beta$-actin loading control, and means \pm SD were calculated to compare the protein levels. (B) Spermatozoa motility was analyzed by spermatozoa analysis system (CASA). (C) Spermatozoa mROS level was determined using MitoSOX Red probes and analyzed using cytoFLEX software. The mean fluorescence intensity (MFI) with MitoSOX Red staining was determined by flow cytometry. (D) The MMP of spermatozoa was determined using JC-1 probes and analyzed by cytoFLEX software. (E) ATP content was analyzed by ATP detection kit. $* \mathrm{P}<0.05$. 
although a slight decrease of ATP contentoccurs in spermatozoa treated with $100 \mu \mathrm{mol} / \mathrm{L}$ Genipin (Fig. 2E). These results indicate that the specific inhibition of UCP2 by Genipin in spermatozoa can down-regulate the motility of spermatozoa, which is probably achieved by either promoting the mROS production or lowering the mROS elimination rather than by blocking the ATP production in human spermatozoa. In addition, the UCP2 protein level in Genipin-treated spermatozoa is slightly reduced compared with the level in nontreated spermatozoa $(P<0.05$, Fig. $2 \mathrm{~A})$, which is likely due to the interference of Genipin with the UCP2 translation process.

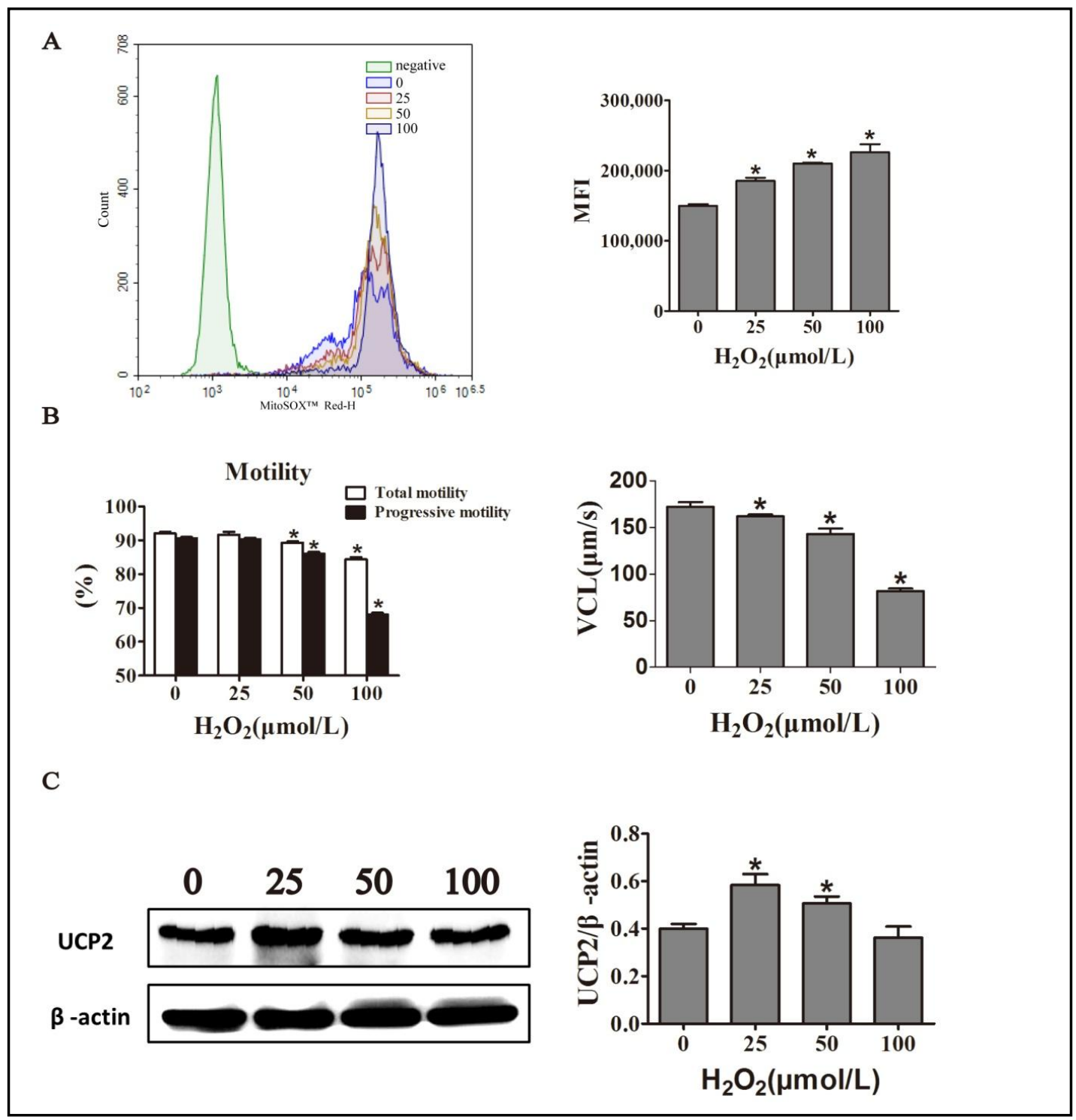

Fig. 3. Effects of $\mathrm{H}_{2} \mathrm{O}_{2}$ treatment on UCP2 expression and spermatozoa motility. (A) Spermatozoa mROS was determined using MitoSOX Red probes and analyzed using cytoFLEX software. The mean fluorescence intensity (MFI) of sperm with MitoSOX Red staining was determined by flow cytometry. (B) Sperm motility was analyzed using sperm analysis system(CASA). (C) Western blot analysis of UCP2. The values were normalized to $\beta$-actin loading control, and means \pm SD were calculated to compare the protein levels. ${ }^{*} \mathrm{P}<0.05$. 
Effect of $\mathrm{H}_{2} \mathrm{O}_{2}$ treatment on UCP2 expression and spermatozoa motility

Many studies have demonstrated that mROS is a critical factor regulating spermatozoa motility. In addition, it has been confirmed that there is a close correlation between UCP2 expression and cellular oxidative stress. However, the role that UCP2 could play in regulating mROS content in spermatozoa remains unclear. To further understand the relevant mechanism, $\mathrm{H}_{2} \mathrm{O}_{2}$ was applied to the spermatozoa for $30 \mathrm{~min}$ with the concentrations ranging from 0 to $100 \mu \mathrm{mol} / \mathrm{L}$ [25]. As expected, the mROS content is significantly increased after $\mathrm{H}_{2} \mathrm{O}_{2}$-treatment $(P<0.05$, Fig. 3A). Meanwhile, the total motility, the progressive motility, and VCL are significantly decreased after $\mathrm{H}_{2} \mathrm{O}_{2}$-treatment compared with controls $(P<0.05$, Fig. 3B). Interestingly, the UCP2 level is significantly elevated in spermatozoa treated with $25 \mu \mathrm{mol} / \mathrm{L}$ and $50 \mu \mathrm{mol} / \mathrm{L} \mathrm{H}_{2} \mathrm{O}_{2}$ compared with controls $(P<0.05$, Fig. 3C), indicating that, within a certain range, mildly excessive ROS can promote UCP2 expression. Combined with the data obtained in the Genipin-treatment experiments, it is clearly shown that the elevation of UCP2 expression is helpful for the maintenance of mROS content at a normal physiological level and thus mitigates the negative impact of ROS on spermatozoa motility.

\section{Effect of ROS scavenger on UCP2 expression and spermatozoa motility}

To illuminate whether ROS scavengers can affect UCP2 expression or spermatozoa motility, $N$-acetyl-L-cysteine (NAC), a widelyused ROS scavenger, was used in this study. The concentration and duration of NAC treatment were determined in a spermatozoa viability experiment (data not shown). As expected, the level of spermatozoa mROS is reduced after NAC treatment (Fig. 4A). In addition, as shown in Fig. 4B, a significant increase is observed in the VCL mobility in the treatments with $50 \mu \mathrm{mol} / \mathrm{L}$ and $100 \mu \mathrm{molL}$ NAC $(P<0.05)$. However, there is no significant difference of UCP2 levels between NAC-treated and nontreated

Fig. 4. Effects of NAC treatment on UCP2 expression and spermatozoa motility. (A) Sperm mRos was determined using MitoSOX Red. The mean fluorescence intensity (MFI) of sperm with MitoSOX Red staining was determined by flow cytometry. (B) UCP2 protein levels was detected by western blot. The optical density values were normalised to $\beta$-actin loading control, and means \pm SD were graphed (relative expression) to semiquantitatively compare the protein levels. (C). Sperm motility and VCL were analyzed using CASA after treatment with different concentration of NAC. ${ }^{*} \mathrm{P}<0.05$.
A

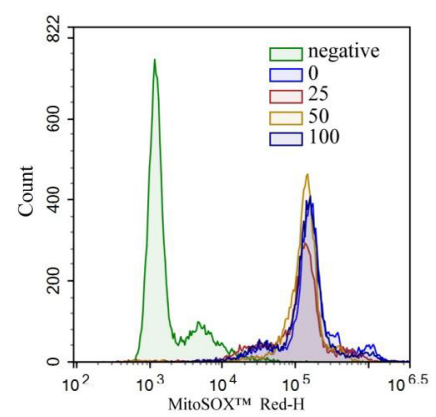

B

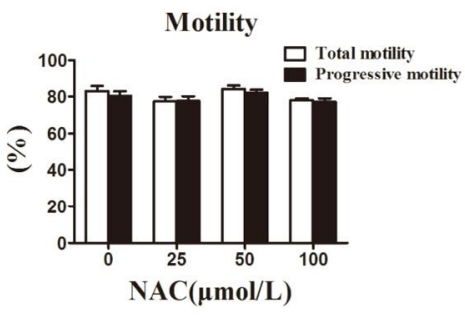

C

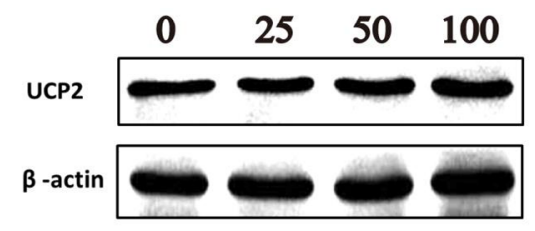

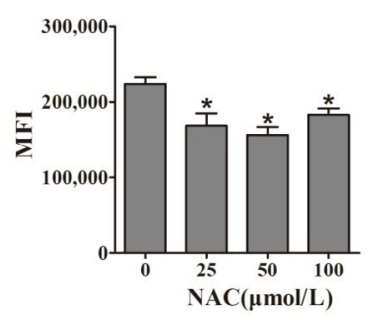
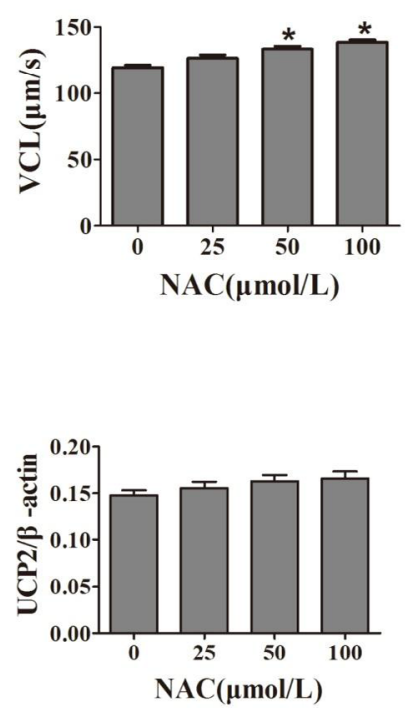


\section{Cellular Physiology Cell Physiol Biochem 2018;50:952-962 \\ \begin{tabular}{l|l|l} 
DOl: 10.1159/000494479 & & $\begin{array}{l}\text { @ } 2018 \text { The Author(s). Published by S. Karger AG, Basel } \\
\text { www.karger.com/cpb }\end{array}$ \\
\hline and Biochemistry
\end{tabular}}

Wang et al.: Roles of UCP2 in Human Spermatozoa

spermatozoa $(P>0.05$, Fig. 4C), indicating that the decrease of mROS level caused by ROS scavenger has no impact on the expression of UCP2. Combined with the data obtained in the experiments involving $\mathrm{H}_{2} \mathrm{O}_{2}$ treatment, we conclude that only mildly excessive mROS can induce an elevated UCP2 expression level, while normal physiological level or a lower level of mROS has no impact on the expression of UCP2 in human spermatozoa.

\section{Discussion}

Poor spermatozoa motility has been found associated with various factors, such as the over-production of ROS [8], mitochondrial dysfunction in energy production (i.e. the abnormalities in levels of ATP and MMP) [7, 26], excessive DNA fragmentation [27], defective morphology [3], and so on. In the present study, UCP2 is found to have an intimate relationship with spermatozoa motility. The UCP2 expression levels are significantly higher in the NS group than in the AS group, while the specific inhibition of UCP2 by Genipin results in a significant decrease in spermatozoa total motility, progressive motility, and VCL. These observations raise a question: how does UCP2 regulate human spermatozoa motility?

It is known that UCP2 plays vital roles in maintaining cellular mitochondrial homeostasis via regulating energy balance [28], maintaining calcium homeostasis, controlling mROS levels [29, 30], and regulating cellular autophagy and apoptosis [31]. UCP2 can protect cells from oxidative damages via eliminating mROS [30]. Published studies have suggested that a UCP2 homologue, UCP1, regulates ATP production and maintains cellular energy balance in many cell types through uncoupling electron transport and ATP generation [32, 33]. Theoretically, protons pass through the inner mitochondrial membranes and form electrochemical gradientsresulting in the production of ATPs coupled with the production of a large number of mROS [34]. Hence, the content of mROS is positively correlated with the levels of ATP and MMP. A positive correlation between mitochondrial energy function and spermatozoa motility has been demonstrated [14, 26, 35, 36]. In these studies, it was found that the levels of MMP and ATP are significantly higher in the NS group than in the AS group, but the mROS levels show a reverse trend, implying that one special mechanism exists in the NS group to either inhibit mROS production or promote mROS elimination. Interestingly, in the present study, upon the inhibition of UCP2, ATP and MMP levels are found unaffected while the mROS level is observed significantly elevated, indicating that UCP2 may fulfill its function by promoting mROS scavenging rather than by facilitating ATPproduction in human spermatozoa.

To further demonstrate the relationship between UCP2 and the mROS level, $\mathrm{H}_{2} \mathrm{O}_{2}$ and NACwere individually applied to increase and decrease the mROS levels, respectively. The $\mathrm{H}_{2} \mathrm{O}_{2}$-treatment induces an elevated measured mROS level coupled with the impaired spermatozoa mobility as expected. Unexpectedly, the moderate level of $\mathrm{H}_{2} \mathrm{O}_{2}$ can slightly induce the UCP2 expression although highly excessive $\mathrm{H}_{2} \mathrm{O}_{2}$ shows a negative impact on the UCP2 expression. The NAC treatment facilitates the mROS scavenging, but does not have an impact on the UCP2 expression. Combined with the data obtained in the Genipin-treatment of UCP2, it is suggested that an UCP2-mROS-motility regulatory systemexists in human spermatozoa. In this system, the elevation of UCP2 expressioncan enhance spermatozoa motility by promoting mROS scavenging, while slightly over-produced mROS in turn can serve as a feedback signal forthe induction of UCP2 expression. The resultsobtained in the Genipin-, $\mathrm{H}_{2} \mathrm{O}_{2}^{-}$, and NAC-treatment experiments, combined with the observation of higher level of UCP2 expression in the NS group, suggest that the spermatozoa with high motility are more vigorousin mROS scavenging.

Normal physiologicallevels of ROS play roles in spermatogenesis and maturation [37], capacitation [38,39], acrosome reaction [38], and the fusion programme of spermatozoa and oocyte $[37,40,41]$. Nevertheless, excessive ROS will induce severe damagestospermatozoa membrane lipids, DNA, andultra-structures, leading to a decreased spermatozoa motility and the subsequent infertility $[8,37,42]$. Several antioxidant enzymes, such as catalase 
(CAT), superoxide dismutase (SOD), and glutathione peroxidase (GPX), were detected in the seminal plasma $[43,44]$. However, few intracellular antioxidant mechanisms were discerned in spermatozoa. In this study, the results demonstrate that UCP2 plays a pivotal rolein ROS scavenging in human spermatozoa, and thus affects spermatozoa motility.

Recently, a research group observed similar effects of UCP2 expression in the spermatozoa of zebrafish and yellow catfish $[22,23]$. It was found that a UCP2 promoter significantly improved the viability of post-thaw spermatozoa, accompanied by the decreased levels of ROS and MDA [23]. The UCP2 expression in the zebrafish spermatozoa can be down-regulated by Genipin [30] consistent with our observation in humanspermatozoa, and furthermore, could be up-regulated by acute cold exposure [30]. It is noteworthy that the spermatozoaare terminally differentiated cells, with DNA tightly compacted in the head, most of organelles removed during spermatozoa maturation, and only a few organelles such as mitochondria retained. In addition, it is believed that the spermatozoa lack transcription and translation systems. Nevertheless, Gur et al. (2006) showed mitochondrial ribosomes are actively involved in protein translation during capacitation of spermatozoa. Moreover, they confirmed that the nuclear-encoded mRNA in spermatozoa could be translated on the spermatozoa mitochondrial ribosomes, and such an ability of translation is related to the spermatozoa viability, motility, capacitation, and acrosome reaction [45]. These studies proved that matured spermatozoa retain the ability of self-regulation, which can explain why the UCP2 expression in human spermatozoa can be regulated by Genipin and $\mathrm{H}_{2} \mathrm{O}_{2}$. These evidences further support the existence of UCP2 regulation system in human spermatozoa.

\section{Conclusion}

In summary, in this study, it is the first time to demonstrate the existence of an UCP2mROS-motility regulatory system in human spermatozoa. UCP2 protein is expressed in human spermatozoa, and regulates spermatozoa motility. UCP2 controls mROS levels by promoting mROS elimination, and mildly over-produced mROS serving as a signal can induce the UCP2 expression. Therefore,the exploitationand regulation of UCP2-mROS system might pose a new strategy to treat patients with poor spermatozoa motility. However, for this purpose, more studies with the aim of revealing the in-depth mechanism of the UCP2-mROS-motility regulatory system and its roles in regulating other functions in spermatozoa are needed.

\section{Disclosure Statement}

The authors declared that no competing interests exist.

\section{Acknowledgements}

This work was supported by grants from the Natural Science Foundation of China (81501312, 81771586), the Natural Science Foundation of Jiangsu province (BK20171317).

\section{References}

\footnotetext{
1 Boivin J, Bunting L, Collins JA,Nygren KG: International estimates of infertility prevalence and treatmentseeking: potential need and demand for infertility medical care. Hum Reprod 2007;22:1506-1512.
} 


\section{Cellular Physiology Cell Physiol Biochem 2018;50:952-962 \begin{tabular}{ll|l} 
and Biochemistry & $\begin{array}{l}\text { DOI: 10.1159/000494479 } \\
\text { Published online: } 23 \text { October } 2018\end{array}$ & $\begin{array}{l}\text { (c) } 2018 \text { The Author(s). Published by S. Karger AG, Basel } \\
\text { www.karger.com/cpb }\end{array}$
\end{tabular}}

Wang et al.: Roles of UCP2 in Human Spermatozoa

- Hajder M, Hajder E.Husic A: The Effects of Total Motile Sperm Count on Spontaneous Pregnancy Rate and Pregnancy After IUI Treatment in Couples with Male Factor and Unexplained Infertility. Med Arch 2016;70:39-43.

- Z Zhang ZH, Zhang HG, Dong Y, Han RR, Dai RL,Liu RZ: Ureaplasma urealyticum in male infertility in Jilin Province, North-east China, and its relationship with sperm morphology. J Int Med Res 2011;39:33-40.

4 Donnelly ET, Lewis SEM, McNally JA,Thompson W: In vitro fertilization and pregnancy rates: the influence of sperm motility and morphology on IVF outcome. Fertil Steril 1998;70:305-314.

5 Butcher MJ, Janoo J, Broce M, Seybold DJ, Gantt P,Randall G: Use of Sperm Parameters to Predict Clinical Pregnancy with Intrauterine Insemination. J Reprod Med 2016;61:263-269.

6 Ferlin A, Menegazzo M, Gianesello L, Selice R,Foresta C: Effect of relaxin on human sperm functions. J Androl 2012;33:474-482.

7 Perchec G, Jeulin C, Cosson J, André F,Billard R: Relationship between sperm ATP content and motility of carp spermatozoa. J Cell Sci 1995;108:747-753.

8 Agarwal A, Saleh RA.Bedaiwy MA: Role of reactive oxygen species in the pathophysiology of human reproduction. Fertil Steril 2003;79:829-843.

-9 Desai N, Sabanegh E, Jr., Kim T,Agarwal A: Free radical theory of aging: implications in male infertility. Urology 2010;75:14-19.

10 Bergamo P, Volpe MG, Lorenzetti S, Mantovani A, Notari T, Cocca E, Cerullo S, Di Stasio M, Cerino P,Montano L: Human semen as an early, sensitive biomarker of highly polluted living environment in healthy men: A pilot biomonitoring study on trace elements in blood and semen and their relationship with sperm quality and RedOx status. Reprod Toxicol 2016;66:1-9.

11 Jurewicz J, Radwan M, Sobala W, Polanska K, Radwan P, Jakubowski L, Ulanska A,Hanke W: The relationship between exposure to air pollution and sperm disomy. Environ Mol Mutagen 2015;56:50-59.

$>12$ Rubes J, Selevan SG, Evenson DP, Zudova D, Vozdova M, Zudova Z, Robbins WA,Perreault SD: Episodic air pollution is associated with increased DNA fragmentation in human sperm without other changes in semen quality. Hum Reprod 2005;20:2776-2783.

13 Agnihotri SK, Agrawal AK, Hakim BA, Vishwakarma AL, Narender T, Sachan R,Sachdev M: Mitochondrial membrane potential (MMP) regulates sperm motility. In vitro Cell Dev Biol Anim 2016;52:953-960.

14 Cassina A, Silveira P, Cantu L, Montes JM, Radi R,Sapiro R: Defective Human Sperm Cells Are Associated with Mitochondrial Dysfunction and Oxidant Production. Biol Reprod 2015;93:119.

15 Mundy AJ, Ryder TA.Edmonds DK: Asthenozoospermia and the human sperm mid-piece. Hum Reprod 1995;10:116-119.

16 Koppers AJ, De Iuliis GN, Finnie JM, McLaughlin EA,Aitken RJ: Significance of mitochondrial reactive oxygen species in the generation of oxidative stress in spermatozoa. J Clin Endocrinol Metab 2008;93:3199-3207.

17 Treulen F, Uribe P, Boguen R,Villegas JV: Mitochondrial permeability transition increases reactive oxygen species production and induces DNA fragmentation in human spermatozoa. Hum Reprod 2015;30:767776.

-18 Andrews ZB, Liu ZW, Walllingford N, Erion DM, Borok E, Friedman JM, Tschop MH, Shanabrough M, Cline G, Shulman GI, Coppola A, Gao XB, Horvath TL,Diano S: UCP2 mediates ghrelin's action on NPY/AgRP neurons by lowering free radicals. Nature 2008;454:846-851.

19 Shaheen A.Aljebali AM: A hypothetical model to solve the controversy over the involvement of UCP2 in palmitate-induced beta-cell dysfunction. Endocrine 2016;54:276-283.

$\checkmark 20$ Kasahara E, Sekiyama A, Hori M, Kuratsune D, Fujisawa N, Chida D, Hiramoto K, Li J, Okamura H, Inoue M,Kitagawa S: Stress-Induced Glucocorticoid Release Upregulates Uncoupling Protein-2 Expression and Enhances Resistance to Endotoxin-Induced Lethality. Neuroimmunomodulation 2015;22:279-292.

21 Brand MD.Esteves TC: Physiological functions of the mitochondrial uncoupling proteins UCP2 and UCP3. Cell Metab 2005;2:85-93.

22 Wang G, Kang N, Gong H, Luo Y, Bai C, Chen Y, Ji X, Huang C,Dong Q: Upregulation of uncoupling protein Ucp2 through acute cold exposure increases post-thaw sperm quality in zebrafish. Cryobiology 2015;71:464-471.

-23 Fang L, Bai C, Chen Y, Dai J, Xiang Y, Ji X, Huang C,Dong Q: Inhibition of ROS production through mitochondria-targeted antioxidant and mitochondrial uncoupling increases post-thaw sperm viability in yellow catfish. Cryobiology 2014;69:386-393. 


\section{Cellular Physiology Cell Physiol Biochem 2018;50:952-962 \begin{tabular}{ll|l} 
and Biochemistry Published online: 23 October 2018 & $\begin{array}{l}\odot \text { 2018 The Author(s). Published by S. Karger AG, Basel } \\
\text { www.karger.com/cpb }\end{array}$ \\
\hline
\end{tabular}}

Wang et al.: Roles of UCP2 in Human Spermatozoa

24 Fu Z, Zhou W, Chen X, Li X,Tan Z: Uncoupling protein2 combats oxidative damage to human sperm. Zhonghua Nankexue Zazhi 2010;16:516-519.

-25 Mahfouz RZ, du Plessis SS, Aziz N, Sharma R, Sabanegh E,Agarwal A: Sperm viability, apoptosis, and intracellular reactive oxygen species levels in human spermatozoa before and after induction of oxidative stress. Fertil Steril 2010;93:814-821.

26 Chai RR, Chen GW, Shi HJ, O WS, Martin-DeLeon PA,Chen H: Prohibitin involvement in the generation of mitochondrial superoxide at complex I in human sperm. J Cell Mol Med 2017;21:121-129.

-27 Vandekerckhove FW, De Croo I, Gerris J, Vanden Abbeel E,De Sutter P: Sperm Chromatin Dispersion Test before Sperm Preparation Is Predictive of Clinical Pregnancy in Cases of Unexplained Infertility Treated with Intrauterine Insemination and Induction with Clomiphene Citrate. Front Med (Lausanne) 2016;3:63.

28 Cheng G, Polito CC, Haines JK, Shafizadeh SF, Fiorini RN, Zhou X, Schmidt MG,Chavin KD: Decrease of intracellular ATP content downregulated UCP2 expression in mouse hepatocytes. Biochem Biophys Res Commun 2003;308:573-580.

29 Jezek P, Olejar T, Smolkova K, Jezek J, Dlaskova A, Plecita-Hlavata L, Zelenka J, Spacek T, Engstova H, Pajuelo Reguera D,Jaburek M: Antioxidant and regulatory role of mitochondrial uncoupling protein UCP2 in pancreatic beta-cells. Physiol Res 2014;63 Suppl 1:S73-91.

30 Ge H, Zhang F, Shan D, Chen H, Wang X, Ling C, Xi H, Huang J, Zhu C,Lv J: Effects of Mitochondrial Uncoupling Protein 2 Inhibition by Genipin in Human Cumulus Cells. Biomed Res Int 2015;2015:323246.

-31 Lou J, Wang Y, Wang X,Jiang Y: Uncoupling protein 2 regulates palmitic acid-induced hepatoma cell autophagy. Biomed Res Int 2014;2014:810401.

-32 Echtay KS: Mitochondrial uncoupling proteins--what is their physiological role? Free Radic Biol Med 2007;43:1351-1371.

-33 Klingenberg M: Uncoupling protein--a useful energy dissipator. J Bioenerg Biomembr 1999;31:419-430.

-34 Schultz BE, Chan SI: Structures and proton-pumping strategies of mitochondrial respiratory enzymes. Annu Rev Biophys Biomol Struct 2001;30:23-65.

-35 Swegen A, Lambourne SR, Aitken RJ,Gibb Z: Rosiglitazone Improves Stallion Sperm Motility, ATP Content, and Mitochondrial Function. Biol Reprod 2016;95:107.

-36 Davila MP, Munoz PM, Bolanos JM, Stout TA, Gadella BM, Tapia JA, da Silva CB, Ferrusola CO,Pena FJ: Mitochondrial ATP is required for the maintenance of membrane integrity in stallion spermatozoa, whereas motility requires both glycolysis and oxidative phosphorylation. Reproduction 2016;152:683-694.

37 Kothari S, Thompson A, Agarwal A,du Plessis SS: Free radicals: their beneficial and detrimental effects on sperm function. Indian J Exp Biol 2010;48:425-435.

38 Rivlin J, Mendel J, Rubinstein S, Etkovitz N,Breitbart H: Role of hydrogen peroxide in sperm capacitation and acrosome reaction. Biol Reprod 2004;70:518-522.

39 de Lamirande E.Gagnon C: Human sperm hyperactivation and capacitation as parts of an oxidative process. Free Radic Biol Med 1993;14:157-166.

40 Wathes DC, Abayasekara DR.Aitken RJ: Polyunsaturated fatty acids in male and female reproduction. Biol Reprod 2007;77:190-201.

-41 Aitken RJ, Clarkson JS.Fishel S: Generation of reactive oxygen species, lipid peroxidation, and human sperm function. Biol Reprod 1989;41:183-197.

42 Saleh RA, Agarwal A, Nada EA, El-Tonsy MH, Sharma RK, Meyer A, Nelson DR,Thomas AJ: Negative effects of increased sperm DNA damage in relation to seminal oxidative stress in men with idiopathic and male factor infertility. Fertil Steril 2003;79 Suppl 3:1597-1605.

43 Smith R, Vantman D, Ponce J, Escobar J,Lissi E: Total antioxidant capacity of human seminal plasma. Hum Reprod 1996;11:1655-1660.

44 Kobayashi T, Miyazaki T, Natori M,Nozawa S: Protective role of superoxide dismutase in human sperm motility: superoxide dismutase activity and lipid peroxide in human seminal plasma and spermatozoa. Hum Reprod 1991;6:987-991.

45 Gur Y, Breitbart H: Mammalian sperm translate nuclear-encoded proteins by mitochondrial-type ribosomes. Genes Dev 2006;20:411-416. 